\title{
Peer-review Statement
}

All papers published in this volume of Unri Conference Series have been peer reviewed through processes administered by the conference committee. Reviews were conducted by expert referees to the professional and scientific standards expected of a proceedings journal published by Universitas Riau. 